\title{
Dynamic design model of displacement ventilation
}

\author{
Natalia Lastovets $^{1, *}$, Risto Kosonen ${ }^{1,2}$, Juha Jokisalo ${ }^{1}$ and Simo Kilpeläinen ${ }^{1}$ \\ ${ }^{1}$ Aalto University, Department of mechanical engineering, Sähkömiehentie 4, 00076 Espoo, Finland \\ 2. College of Urban Construction, Nanjing Tech University, China
}

\begin{abstract}
An accurate temperature gradient calculation is essential for displacement ventilation (DV) system design, since it directly relates to the calculation of the required supply air flow rate. Inaccurate temperature prediction can cause the poor thermal comfort and w sizing of the ventilation and cooling systems. Several simplified nodal models were developed and implemented in the various building simulation software to estimate the temperature stratification in rooms with DV. Recent studies reveal that the multi-nodal models provide the most accurate temperature gradient prediction. However, the most building simulation software uses the air models with only one air node. The present study introduces the dynamic temperature gradient model for DV and investigates the effect of thermal mass on the temperature stratification. The model was validated with the experimental results of the lecture room with displacement ventilation. The room air temperature measurements were conducted during three weeks at 20 different heights. The supply air temperature and occupancy rate were recorded during each scheduled lecture. The developed dynamic nodal model is able to accurately calculate the air temperatures in occupied zone. The effect of the thermal mass and varied heat loads on the indoor air temperature stratification is analysed for the lecture room with DV.
\end{abstract}

\section{Introduction}

In displacement ventilation (DV) systems, cool air is supplied into the occupied zone of the room near the floor at low velocity and then entrained by buoyant plumes over any warm objects. As a result, a two layer room air temperature profile, stratified and mixed, is developed. Ideally, the air movements induced by thermal plumes transport heat and pollutants to the layer above the occupied zone, promoting a vertical temperature and contaminants stratification. The transition level between a mixed upper layer and stratified layer is called mixing height, which is related to the height where the inflow rate matches the airflow induced by the thermal plumes in the occupied zone. Controlling the mixing height position is one of the most challenging tasks in DV system design, since it directly related to the calculation of supply air flow rate.

Several simplified nodal models are developed to calculate temperature gradient in rooms with displacement ventilation [3]. Among the simplified model RC models are the most popular, since their parameters have obvious physical meanings and the models require less data than data-driven models. Based on circuit principles and Kirchhoff electric current theory, constructing building models with RC-networks implies representing every element of the building with resistors and capacitors. The simplest one-capacity models are not able to represent accurately the indoor air temperature dynamics, since the real physical process behaves like a two- or higher order system. In addition, several studies show that higher order models are more accurate than the first order RC models in capturing thermal behaviour of a building [1]. The building envelope RC models usually consist of at least three wall resistances and two [2] or four [1] capacitances. These models are usually suitable to predict dynamic indoor and outdoor heat pulses and working insufficiently with lasting thermal loads. The purpose of this article is to introduce the simplified RC 2-capacity model and validate it with the building energy programme.

Defining of heat capacities and conductances is a complicated issue since it depends on many parameters of building heat transfer. In this study, the IDA ICE simulation results were used to calibrate the conductances and capacitances in the RC-model so that the thermal behaviour in RC-model matched with the results from reference model built in IDA ICE. This study uses the calibration methodology developed by Kai Siren [4].

\section{Methods}

\subsection{Simplified 2-capacity model}

This section present the simplified two-capacity model to assess the indoor air temperature dynamics. The RCmodel was initially developed by Kai Siren [4].The structure of the proposed model is shown in Fig.1.

\footnotetext{
* Corresponding author: natalia.lastovets@aalto.fi
} 


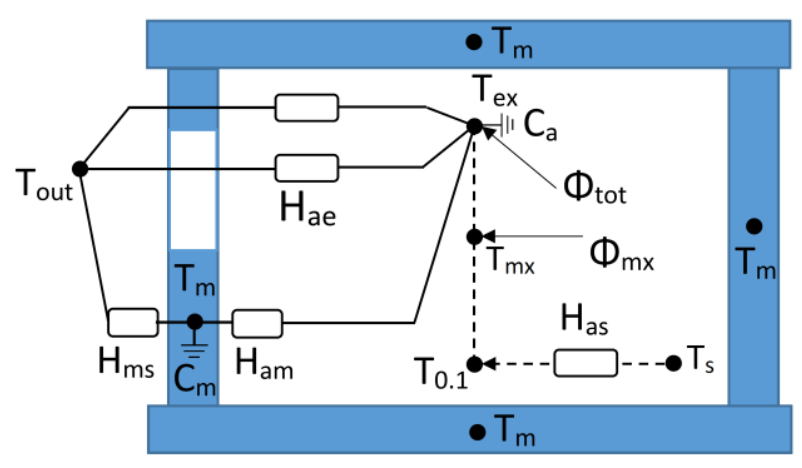

Fig. 1. Structure of the simplified 2-capacity model (Siren, 2016)

Displacement ventilation based on cool air supply to the lower part of the room provides vertical indoor temperature stratification, so that one air node is not enough to represent the indoor air balance. Thus, the nodal model to calculate the temperature gradient in rooms with DV is applied [5]. The model calculates three air temperatures: along the floor at the height $0.1 \mathrm{~m} \mathrm{t} 0.1$, at the level of mixing height $\mathrm{T}_{\mathrm{mx}}$ and the exhaust temperature $\mathrm{T}_{\mathrm{ex}}$. The internal heat loads are divided to the mixing height level and the height of exhaust air. The mixing height level is calculated with the validated plume theory methods $[1,6]$.

The inputs of the models are the external outdoor air temperature $T_{e}$, , the ventilation supply air temperature $T_{s}$, the air flow rate $\mathrm{q}_{\mathrm{v}}$ and the internal heat loads. The internal heat loads are divided to the mixing height level and the height of exhaust air. In the model, there is two capacities: conductances of room air $\mathrm{C}_{\mathrm{a}}$ and building thermal mass $\mathrm{C}_{\mathrm{m}}$. The mass capacity $\mathrm{C}_{\mathrm{m}}$ is related to the thermal mass in the room structures and furniture. The model includes the heat capacity flow through ventilation $\mathrm{H}_{\mathrm{as}}$, heat conductances of window $\mathrm{H}_{\mathrm{ae}}$; between mass node and outdoor air node point $\mathrm{H}_{\mathrm{ms}}$ and between mass node and indoor air node point Ham. Both conductances $\mathrm{H}_{\mathrm{ms}}$ and $\mathrm{H}_{\mathrm{am}}$ contain heat conduction in the solid wall material as well as convection on the surfaces. The mass node point is located in an undefined depth inside the building structure and represents a mean temperature of the active building mass. The capacities $\mathrm{C}_{\mathrm{a}}$ and $\mathrm{C}_{\mathrm{m}}$ and the conductances $\mathrm{H}_{\mathrm{ms}}$ and $\mathrm{H}_{\mathrm{am}}$ are calibrated so that indoor air temperature calculated with the 2-capacity matches the results of the detailed building simulation model.

The energy balance for the indoor air node and thermal mass temperatures arefollowing:

$$
\begin{gathered}
C_{a} \cdot d T_{a} / d t=H_{a e}\left(T_{e}-T_{a}\right)+H_{a m}\left(T_{m}-T_{a}\right)+ \\
+H_{a v}\left(T_{s}-T_{a}\right)+\Phi_{t o t} \\
C_{m} \cdot d T_{m} / d t=H_{a m}\left(T_{e}-T_{a}\right)+H_{m s}\left(T_{s}-T_{m}\right)
\end{gathered}
$$

where $\mathrm{dT}_{\mathrm{a}}$ is the temperature differential and $\mathrm{dt}$ is the time differential. $\Phi_{\text {tot }}$ is the total heat loads.

In displacement ventilation, this indoor temperature corresponds to the exhaust air temperature.

Since the thermal mass effect on the room temperature with DV is the same as with mixing ventilation, the indoor temperatures in displacement ventilation have a tendency to change with the same rule, it is possible to apply 2-capacity model to calculate temperature gradient in the case of displacement ventilation. In this case, the total the heat load $\Phi_{\text {tot }}$ is divided to the heat load in two parts: low and high heat loads $\Phi_{\text {low }}$ and $\Phi_{\text {high. }}$ Low heat loads are considered to be the ones that occur in the occupied zone of the room, whereas high heat loads are located near the ceiling. The examples of low heat loads are the ones from people and office equipment. The high heat loads in practice could be from lighting units, warm ceiling or solar gains through high-located windows. The low heat loads are located the mixing height that in the case of DV is calculated with plume theory correlations [3].

\subsection{Calibration of the capacitance model}

The heat conductances and heat capacitances expressed in heat balance equations 1-2 need to be determined when modelling a building with RC-model. In this study, the IDA ICE simulation results were used to calibrate the conductances and capacitances in RC-model so that the thermal behaviour in RC-model matched with the results from advanced model built in IDA ICE [7].

\subsubsection{The IDA-ICE model of the study case}

The building model was formed using IDA indoor Climate and Energy 4.0 (IDA-ICE) building simulation software. This software allows modelling of the building, HVAC-systems, internal loads, outdoor climate, etc. and provides simultaneous dynamic simulation of heat transfer and mass flows. It is a suitable tool for the simulation of thermal comfort, indoor air quality, and energy consumption in complex buildings.

A modular simulation environment, IDA-ICE, has been developed by the Division of Building Services Engineering, KTH, and the Swedish Institute of Applied Mathematics, ITM $[8,9]$. The mathematical models are described in terms of equations in a formal language using non-negative matrix factorization. The IDA-ICE simulation software was validated both empirically [10] and via several independent inter-model comparisons [11]. In addition, Kropf and Zweifel [12] validated IDAICE according to the European Standard prEN 13791. The standard defines the test cases: heat conduction through opaque walls, internal long wave radiation exchange, shading of windows by external constructions, and a test case for the whole calculation method. After simplification of the model, IDA-ICE gave the results as demanded by the standard.

The studied lecture room was built in IDA-ICE with the use of the information from the architectural and engineering projects. Since the software does allows building only "show box" rooms, the sizes of the model was adjusted from the volume of the room (Fig.2) 

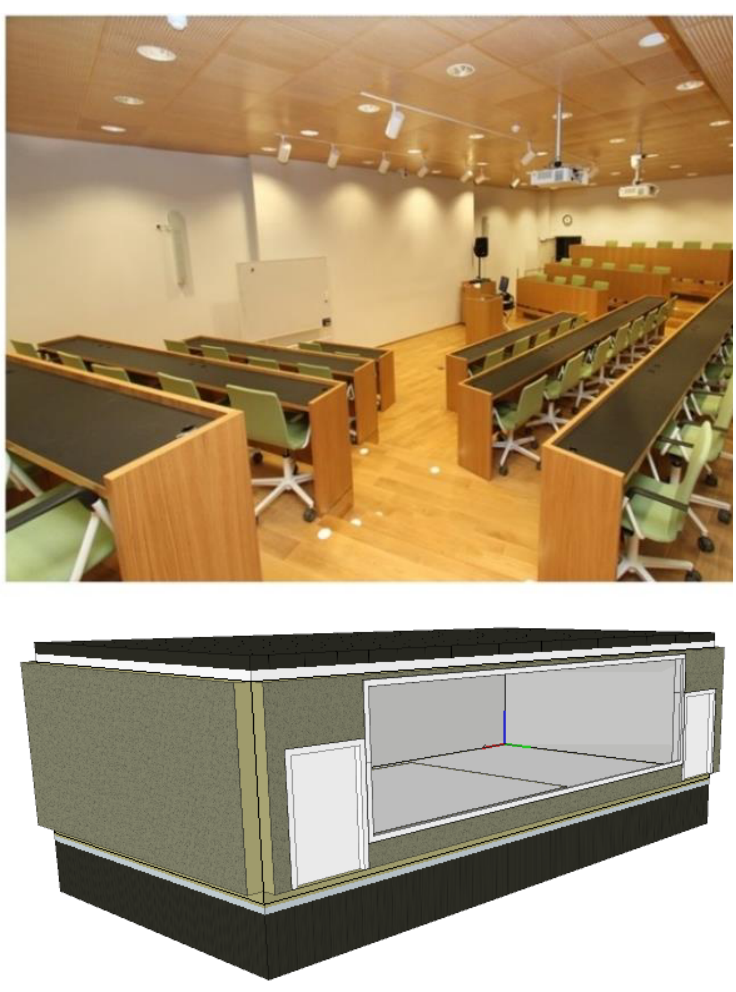

Fig. 2. Photo of the studied lecture room and the IDA-ICE model of it.

Table 1. Constructional and system parameters of the study case

\begin{tabular}{|l|c|c|}
\hline Parameter & Value & unit \\
\hline Net floor area & 86.4 & $\mathrm{~m}^{2}$ \\
\hline Total internal surface area & 289.2 & $\mathrm{~m}^{2}$ \\
\hline Internal volume & 256.5 & $\mathrm{~m}^{3}$ \\
\hline Internal heat gains & 0.0 & $\mathrm{~W} / \mathrm{m}^{2}$ \\
\hline Total conductance of structures & 95.2 & $\mathrm{~W} / \mathrm{K}$ \\
\hline Window total conductance & 45.4 & $\mathrm{~W} / \mathrm{K}$ \\
\hline Leakage air flow & 0.0 & $\mathrm{~m}^{3} / \mathrm{s}$ \\
\hline Supply air flow & 0.6 & $\mathrm{~m}^{3} / \mathrm{s}$ \\
\hline Supply air temperature & 18.0 & ${ }^{\circ} \mathrm{C}$ \\
\hline
\end{tabular}

\subsubsection{Steady-state parameter identification}

In steady state parameter identification, the steady state energy balance was matched with the indoor air node point to fix the conductance values of the 2-capacity model. The internal heat loads were not applied in the models since they are not needed in the calibration. The IDA-ICE simulation program generates the reference data for the steady state conditions. Conductance values were calculated by running the IDA ICE model with artificial weather file were all the parameters, such as outdoor air temperatures, wind speed, had constant values. Since the calibrated lecture hall does not have external walls, the outdoor temperatures should be positive, but lower than the normal designed indoor temperature. At the same time, the temperature difference $5{ }^{\circ} \mathrm{C}$ is chosen to avoid computational errors. Three different values of outdoor temperatures $\left(+10{ }^{\circ} \mathrm{C},+15{ }^{\circ} \mathrm{C},+20{ }^{\circ} \mathrm{C}\right)$ were used to get an average performance that are outdoor temperature dependent such as heat transfer coefficients and window Uvalues.

The simulation with the IDA ICE model with constant outdoor parameters has to carry out long enough, so that the building reached steady-state condition, from which the conductance values and the heat capacity flows could be determined. In order to keep the indoor air set point temperature $21^{\circ} \mathrm{C}$, the ideal heater is applied with the maximum power $5 \mathrm{~kW}$.

The conductance values of window $\mathrm{H}_{\mathrm{ae}}$ is inserted directly from the IDA-ICE model. Since the conductances on both sides of the mass node, $\mathrm{H}_{\mathrm{am}}$ and $\mathrm{H}_{\mathrm{ms}}$ can be determined only in the dynamic identification stage, in the steady-state identification they are merged to one total wall conductance. The combination of conductances was performed following the thermal resistance series connection:

$$
H_{a m s}=\left(1 / H_{a m}+1 / H_{m s}\right)^{-1}
$$

The correct value for $\mathrm{H}_{\mathrm{ams}}$ was calculated from the minimum error in heating powers resulting from air node energy balance between the IDA ICE and the RC-model at the three different outdoor temperatures. Parameters from the steady-state identification together with the calibration parameters are presented in Table 2 .

Table 2. Calculated model parameters from steady-stare identification

\begin{tabular}{|c|c|}
\hline Parameter & Value \\
\hline $\mathrm{H}_{\mathrm{as}}$ & $726 \mathrm{~W} / \mathrm{K}$ \\
\hline $\mathrm{H}_{\mathrm{ae}}$ & $45 \mathrm{~J} / \mathrm{K}$ \\
\hline $\mathrm{H}_{\mathrm{ams}}$ & $102 \mathrm{~J} / \mathrm{K}$ \\
\hline
\end{tabular}

\subsubsection{Dynamic parameter identification}

The dynamic parameter identification was performed after the steady-state one. The purpose of the dynamic parameter identification was to determine the air and mass heat capacities $C_{a}$ and $C_{m}$ and the conductances on the both sides from the mass node and indoor air node point $\mathrm{H}_{\mathrm{am}}$. The conductance $\mathrm{H}_{\mathrm{ms}}$ is then obtained from the Eq 3 .

In the presented calibration, the simulated identification sequence had first a 167 -hour one-week period for stabilizing the temperatures, a 6 hours interruption in the heating power and a second one-week period to check the final temperature level and the heating power will reach steady-state values. The IDA-ICE reference simulations were again performed in three different outdoor air temperatures $\left(10^{\circ} \mathrm{C}, 15^{\circ} \mathrm{C}, 20^{\circ} \mathrm{C}\right)$ with the correspondent recording of the air temperatures and heating powers. Figure 3 presents the results of the 2-capacity model calibration. 
Outdoor air temperature $\left(\mathrm{T}_{\text {out }}=10^{\circ} \mathrm{C}\right)$

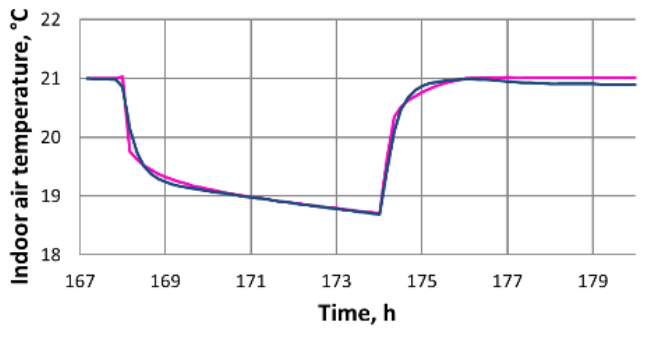

\section{Outdoor air temperature $\left(\mathrm{T}_{\text {out }}=15^{\circ} \mathrm{C}\right)$}

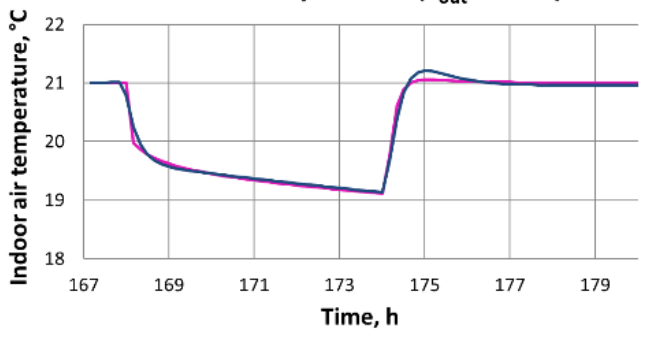

Outdoor air temperature $\left(\mathrm{T}_{\text {out }}=20^{\circ} \mathrm{C}\right)$

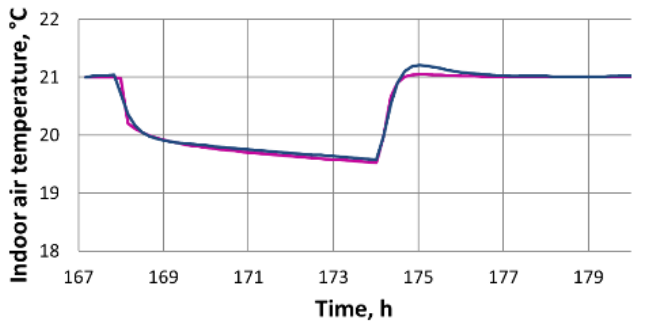

-IDA-ICE model _-capacity model

Fig.3. Calibration results of 2-capacity model.

In the dynamic parameter identification, three parameters $\left(\mathrm{H}_{\mathrm{am}}, \mathrm{C}_{\mathrm{m}}, \mathrm{C}_{\mathrm{a}}\right)$ were to be determined based on the IDA reference simulations (Table 3 ). In dynamic parameter identification, the room air temperature between the models was used as identification criteria to find values for $\mathrm{H}_{\mathrm{am}}, \mathrm{C}_{\mathrm{m}}$ and $\mathrm{C}_{\mathrm{a}}$. The dynamic calibration was defined as a minimization problem, where the average absolute differences between air temperatures in IDA model and $\mathrm{RC}$-model from the simulations with three different outdoor temperatures were minimized.

Table 3. Calculated model parameters

\begin{tabular}{|c|c|}
\hline Parameter & Value \\
\hline $\mathrm{H}_{\mathrm{am}}$ & $1431 \mathrm{~W} / \mathrm{K}$ \\
\hline $\mathrm{C}_{\mathrm{a}}$ & $1636 \mathrm{~kJ} / \mathrm{K}$ \\
\hline $\mathrm{C}_{\mathrm{m}}$ & $48701 \mathrm{~kJ} / \mathrm{K}$ \\
\hline
\end{tabular}

\subsection{Validation of the model with physical measurements}

The measurements of indoor air temperature were carried out between $27^{\text {th }}$ of October and $1^{\text {st }}$ of December 2017 in the lecture room of Aalto University. The main characteristics of the classroom are summarized in Table 4. Images of the room together with a sketch of the layouts are provided in Fig. 4. The exhaust grilles are near the ceiling height and located along the back walls. The supply air flow rate has maximum value when occupancy sensors detect any presence though ventilation rate does not change with number of students present.

The heat loads of people were estimated to be $100 \mathrm{~W}$ per person. The high-levelled heat loads consisted of the lighting units: 40 LED ceiling-mounted lamps and two blackboard lighting units. In both studied cases the lighting heat loads are equal to $3 \mathrm{~kW}$.

Table 4. The lecture hall characteristics

\begin{tabular}{|c|c|c|c|c|}
\hline $\begin{array}{c}\text { Floor } \\
\text { Space } \\
\left(\mathbf{m}^{\mathbf{2}}\right)\end{array}$ & $\begin{array}{c}\text { Seating } \\
\text { capacity }\end{array}$ & $\begin{array}{c}\text { Max. } \\
\text { supply } \\
\text { air } \\
\text { flow } \\
\text { rate } \\
\mathbf{( \mathbf { l } / \mathbf { s } )}\end{array}$ & $\begin{array}{c}\text { Number } \\
\text { and the } \\
\text { type of } \\
\text { supply } \\
\text { diffusers }\end{array}$ & $\begin{array}{c}\text { Number } \\
\text { of the } \\
\text { exhaust } \\
\text { grilles }\end{array}$ \\
\hline 108 & 65 & 600 & $\begin{array}{c}50 \\
\text { underfloor }\end{array}$ & 5 \\
\hline
\end{tabular}

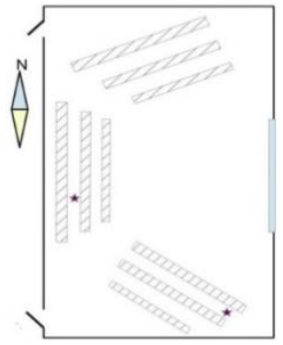

a)

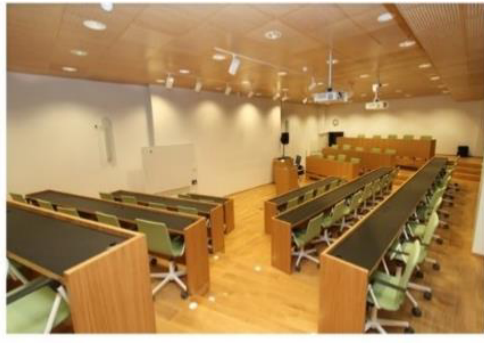

b)
Fig. 4. The validated lecture room; layout a) and photo b)

For measuring temperature at different heights, floor to ceiling, two measuring masts were installed with 20 TinyTag Plus 2 Dual Channel loggers. Seventeen TinyTags were located at $10 \mathrm{~cm}$ distance, starting from 0.1 to $1.7 \mathrm{~m}$, followed by three more at $2,2.5$, and $3 \mathrm{~m}$ respectively. The locations of the measurement masts are marked in Figure 4. A Swema 3000 md manometer was used for measuring air flow rates from individual diffusers.

\section{Results}

The calibrated 2-capacity model was calculated for two cases with different load profiles (Table 5).In the current study, low heat loads $\Phi_{\text {low }}$ are from people and laptops and high heat loads $\Phi_{\text {high }}$ are from lighting units. The supply temperature $T_{\mathrm{v}}$ presented as an average value. Since the lecture hall has no external walls faced to the outdoor air, the temperature Te represents the main temperature of the nearby premises and spaces. Since the studied room is not located over the ground, the ground temperature $T_{g}$ is neglected.

Figures 5 and 7 present measured vertical temperature gradients with marked occupied zone height. 
Figures 6 and 8 present calculated by 2-capacity model and measured air temperatures in two levels: exhaust temperature at the ceiling height level and the occupied zone temperature at the height of $1.1 \mathrm{~m}$. .

Table 5. Constructional and system parameters of the study cases

\begin{tabular}{|l|c|c|c|c|c|}
\hline & $\boldsymbol{\Phi}_{\text {tot }} \mathbf{W}$ & $\begin{array}{c}\boldsymbol{\Phi}_{\text {low }} \\
\mathbf{W}\end{array}$ & $\begin{array}{c}\boldsymbol{\Phi}_{\text {high }} \\
\mathbf{W}\end{array}$ & $\begin{array}{c}\mathbf{T v} \\
{ }^{\circ} \mathbf{C}\end{array}$ & $\begin{array}{c}\mathbf{T e} \\
{ }^{\circ} \mathbf{C}\end{array}$ \\
\hline $\begin{array}{l}\text { Case } \\
1\end{array}$ & 5000 & 2000 & 3000 & 20.2 & 21 \\
\hline $\begin{array}{l}\text { Case } \\
2\end{array}$ & 8000 & 5000 & 3000 & 18.0 & 20.5 \\
\hline
\end{tabular}

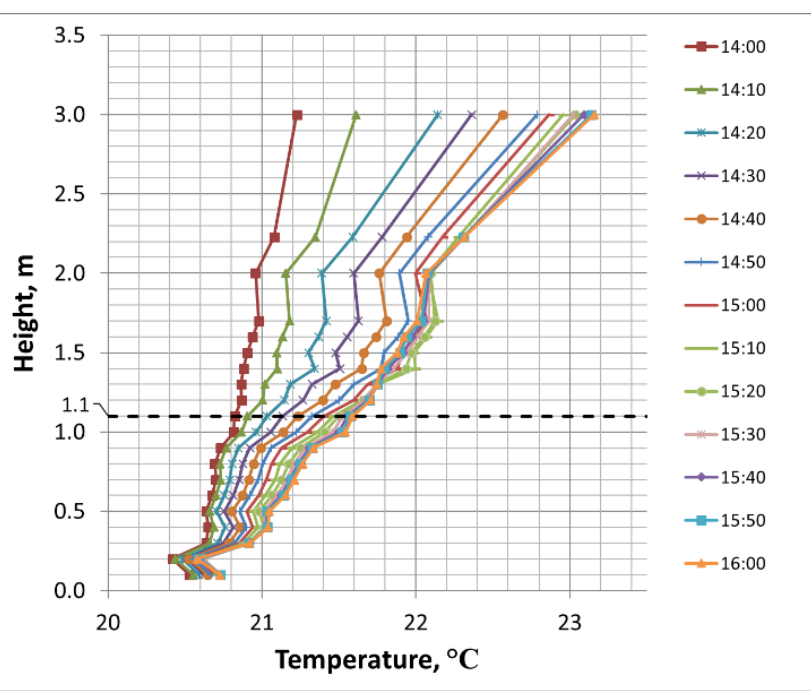

Fig.5. The measured vertical temperature gradient in the Case 1

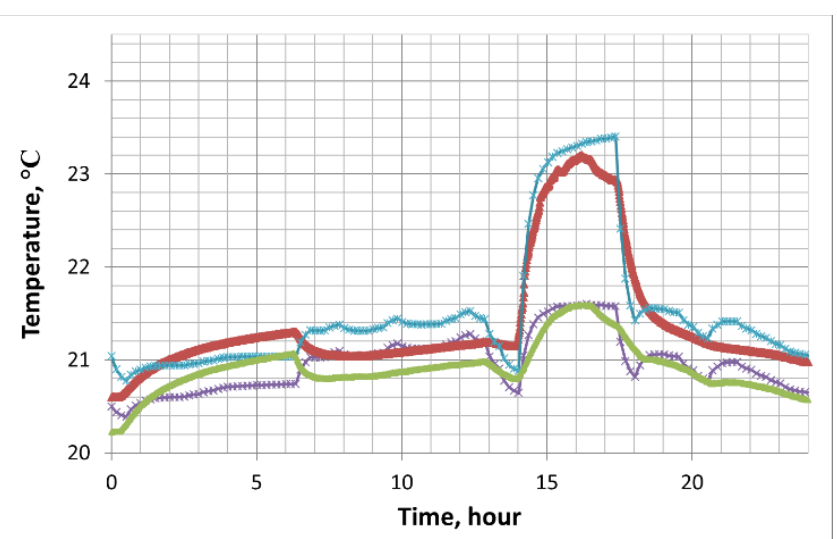

*-Occupied zone temperature 2-cap model - -Exhaust temperature measured

-Occupied zone temperature measured $\quad-$-Exhaust temperature 2-cap model

Fig. 6. The results of two-capacity model simulations and measurements of the Case 1

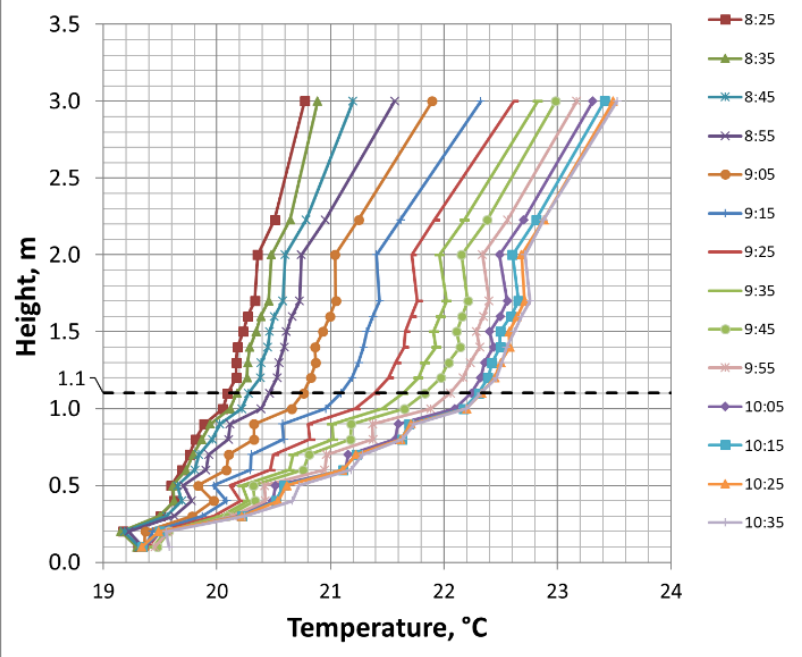

Fig.7. The measured vertical temperature gradient in the Case 2

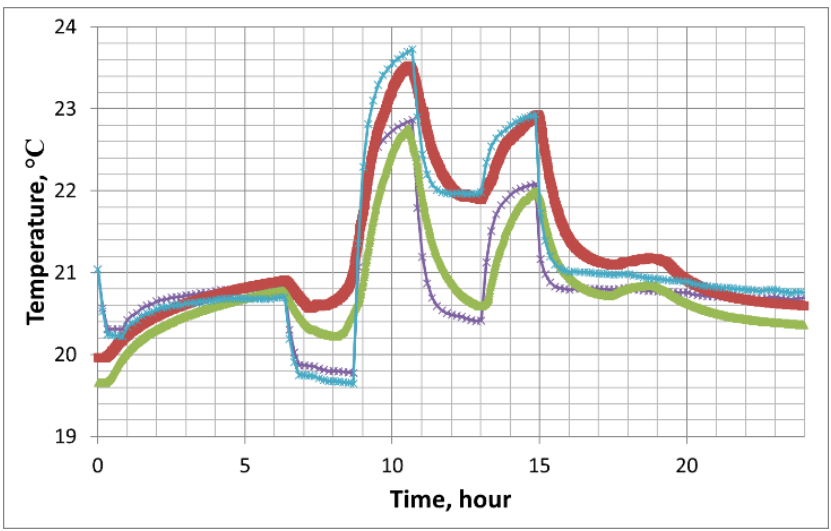

*Occupied zone temperature 2-cap model $\rightarrow$-Exhaust temperature measured

- Occupied zone temperature measured $\quad-$ Exhaust temperature 2-cap model

Fig. 8. The results of two-capacity model simulations and measurements of the Case 1

Figures 5 and 7clearly depict the effect of the heat loads on the vertical temperature gradient. The measured indoor temperatures at different levels demonstrate similar changing trend. In both cases, the 2-capacity DV model predicted well the trends of the indoor air temperatures in all three studied heights. The model was able to account the changing supply temperatures and heat loads. Thus, the calibrated capacities are applicable to the presented 2-capacity model. The important temperatures for displacement ventilation, such as a mixing height temperature $T_{\mathrm{mx}}$ and a temperature along the floor $\mathrm{T}_{0.1}$, were calculated with the high average level of accuracy. In the Case 2, the mixing height temperatures were slightly underestimated. However, in this case it could be related to the uneven internal load distribution.

The results show that the simplified model with lumped building internal mass has good stability to predict the thermal performance for different conditions, because it not only describes the behaviour or performance of the building internal mass but also represents the build- 
ing internal mass with physically meaningful lumped parameters. Thus, the model could be applied for the more accurate in comparison with steady-state modes airflow calculation for sizing displacement ventilation.

\section{Discussion}

The main limitation of the presented model is the uniform outside temperature. In addition to that, all internal mass of the room structures and furniture is presented in the model as one entity. Thus, the model cannot reflect the effects on internal loads caused by the characteristics of different internal masses. In addition, the simplified approach is really well adapted to treat global resolution as the determination of uniform field. Thus, the model is not able to calculate indoor temperature in the cases when significant horizontal temperature gradient occurs in the air zone. Another important drawback of the model as a physical one is that it required detailed description of the physical behaviour, such as meteorological data, geometrical data, thermo-physical variables or else occupancy and equipment scenario. On the other hand, these parameters are usually defined under a certain part of uncertainties. Together with all the limitations induced by the model assumptions, the simplified physical model is getting difficult to evaluate in terms of the accuracy and sensitivity analysis. However, accounting all the limitations, the presented 2-capacity model keeping its computational simplicity demonstrated an acceptable accuracy to calculate the temperature gradient in rooms with DV under dynamic conditions.

\section{Conclusion}

The temperature gradient calculation is very important in DV design, since it directly reflect the airflow rate calculating. Moreover, since building thermal mass significantly effects the internal temperatures, the dynamic thermal model is needed to calculate the vertical temperature gradient in rooms with DV. The model has good robustness to predict the thermal performance under different operation conditions by capturing the dynamic characteristics of the building system correctly. Furthermore, the model is able to take into account time schedules of heat loads. The validation results show that the trained two-capacity model can predict the indoor air temperature gradient in dynamic conditions by capturing the dynamic characteristics of the building system correctly The model can be applied in design DV in various dynamic conditions.

\section{References}

1. Kosonen, R., Lastovets, N., Mustakallio, P., da Graça, G. C., Mateus, N. M., \& Rosenqvist, M. (2016). The effect of typical buoyant flow elements and heat load combinations on room air temperature profile with displacement ventilation. Building and Environment, 108, 207-219.
2. Fraisse, G., Viardot, C., Lafabrie, O., \& Achard, G. (2002). Development of a simplified and accurate building model based on electrical analogy. Energy and buildings, 34(10), 1017-1031.

3. Gouda, M. M., Danaher, S., \& Underwood, C. P. (2002). Building thermal model reduction using nonlinear constrained optimization. Building and environment, 37(12), 1255-1265.

4. Sirén Kai (2016). Course material: A simple model for the dynamic computation of building heating and cooling demand. Espoo, Finland: Aalto University

5. Lastovets, N., Kosonen, R., Mustakallio, P., Jokisalo, J., \& Li, A. (2019). Modelling of room air temperature profile with displacement ventilation. International Journal of Ventilation, 1-15.

6. Mateus, N. M., \& da Graça, G. C. (2015). A validated three-node model for displacement ventilation. Building and Environment, 84, 50-59

7. Mäki A. (2018). Demand response of space heating using model predictive control in an office building. Doctoral thesis. Espoo, Finland: Aalto University.

8. Shalin, P. (1996). Modelling and simulation methods for modular continuous system in buildings. $\mathrm{PhD}$ Thesis. Royal Institute of Technology (KTH), Stockholm, Sweden.

9. Björsell, N., Bring, A., Eriksson, L., Grozman, P., Lindgren, M., Sahlin, P., Shapovalov, A. and Vuolle, M. (1999). IDA indoor climate and energy. In Proc. of the 6-th IBPSA Conference (pp. 10351042).

10. Jokisalo, J., Kalamees, T., Kurnitski, J., Eskola, L., Jokiranta, K., \& Vinha, J. (2008). A comparison of measured and simulated air pressure conditions of a detached house in a cold climate. Journal of Building Physics, 32(1), 67-89.

11. Zweifel, G., \& Achermann, M. (2003). RADTESTthe extension of program validation towards radiant heating and cooling. Building Simulation '03, Eindhoven, Netherlands, 1505-1511.

12. Kropf, S., \& Zweifel, G. (2001). Validation of the Building Simulation Program IDA-ICE According to CEN 13791 "Thermal Performance of BuildingsCalculation of Internal Temperatures of a Room in Summer Without Mechanical Cooling-General Criteria and Validation Procedures". Hochschule Technik+ Architektur Luzern. HLK Engineering. 